\title{
Knowledge and Awareness of School Teachers of Jaipur in Emergency Management of Traumatic Dental Injuries
}

\author{
Yashi Sharma ${ }^{1}$, Bharathi N Padiyar ${ }^{2}$, Mili R Meghpara ${ }^{3}$
}

\begin{abstract}
Introduction: Accidents in the school environment due to falls are very common and are the prime cause of traumatic dental injuries. Hence, it is of great importance to assess the knowledge of people present at the site of accident.

Aim: To evaluate knowledge and awareness of school teachers of Jaipur about emergency management of dental trauma.

Methodology: A custom-made questionnaire was distributed amongst 187 school teachers consisting of three parts. The first part of the questionnaire consisted of personal and professional details. The second part assessed teachers' general knowledge about trauma and its prevalence. The third part consisted of case scenarios about some common traumatic dental injuries (TDIs). Chi-square test was done to describe the strength of the associations.

Results: The overall knowledge of school teachers regarding management of TDIs was found to be satisfactory.

Conclusion: Despite good knowledge and awareness regarding management of dental trauma, school teachers of Jaipur had a good attitude toward learning about management of dental trauma.

Keywords: Emergency, School teachers, Traumatic dental injuries.

Journal of Mahatma Gandhi University of Medical Sciences \& Technology (2021): 10.5005/jp-journals-10057-0186
\end{abstract}

\section{INTRODUCTION}

It is well known that as during recent times, dental trauma has played a significant role in causing dental morbidity and mortality (tooth loss). Andreasen hypothesized that dental trauma, in the future, may exceed dental caries and periodontal diseases. ${ }^{1}$

Nirvan et al. reported that boys are comparatively more affected by traumatic injuries than girls. ${ }^{2}$ It has also been observed that upper central incisors have highest incidents of getting fractured followed by lower central incisors, lower lateral incisors, and upper lateral incisors. ${ }^{3}$

These are situations when the affected person is not capable of providing adequate self-care. These include young children and handicapped individuals; thus, education of caregivers, teachers, sport coaches, is of great importance.

School is one of the locations with the greatest prevalence of traumatic dental injuries. ${ }^{4}$

A significant number of school-aged children experience trauma of some sort to primary or permanent dentition where teachers are generally present at the time dental trauma occurs, as such accidents often take place during or after school activities. ${ }^{5}$ For this, it is required that the first ones contacted by the child after the accident, have proper knowledge and awareness, which will help them to carry out expedite procedures in a timely fashion.

Therefore, it is necessary that not just the parents but also teachers present at the site of the accidents should be well trained in dealing with such unwanted events.

In this study, our aim was to evaluate knowledge and awareness of school teachers in respect to manage the dental trauma, check the background of dental trauma education.

\footnotetext{
${ }^{1-3}$ Department of Pedodontics and Preventive Dentistry, Mahatma Gandhi Dental College \& Hospital, Jaipur, Rajasthan, India

Corresponding Author: Yashi Sharma, Department of Pedodontics and Preventive Dentistry, Mahatma Gandhi Dental College \& Hospital, Jaipur, Rajasthan, India, Phone: +91 9462966602, e-mail: yashi04dec@gmail.com

How to cite this article: Sharma Y, Padiyar BN, Meghpara MR. Knowledge and Awareness of School Teachers of Jaipur in Emergency Management of Traumatic Dental Injuries. J Mahatma Gandhi Univ Med Sci Tech 2021;6(3):102-106.

Source of support: Nil

Conflict of interest: None
}

\section{Methodology}

Firstly, permission from the head of the institutions / principals of the school was obtained. Jaipur city was divided into four zones; north, east, central, and south. A four-page questionnaire form consisting of closed-ended questions in different sections was prepared and distributed amongst 220 teachers of Jaipur.

After obtaining personal and professional information of the teachers, such as name, age, gender, qualification, subject, and years of experience. The questionnaire proceeded with general questions about type of dental injury most commonly encountered. The type of sport most commonly associated with dental trauma etc. The next section consisted of case scenarios, with the first case of uncomplicated crown fracture followed by cases of subluxation and avulsion. The last section consisted of self-assessment questions to

() The Author(s). 2021 Open Access This article is distributed under the terms of the Creative Commons Attribution 4.0 International License (https://creativecommons. org/licenses/by-nc/4.0/), which permits unrestricted use, distribution, and non-commercial reproduction in any medium, provided you give appropriate credit to the original author(s) and the source, provide a link to the Creative Commons license, and indicate if changes were made. The Creative Commons Public Domain Dedication waiver (http://creativecommons.org/publicdomain/zero/1.0/) applies to the data made available in this article, unless otherwise stated. 
see if the teachers were confident enough to handle dental trauma and if they felt a need for an educational seminar regarding the same.

The forms were collected back and were subjected to data analysis. The chi-square test was performed to test the influence of different variables, such as age, gender, teaching experience, and science or nonscience background of the teachers, on knowledge of management of dental trauma, and the level of significance was set at $p=0.05$.

Part 1

Personal and Professional Information:

- Name-

- Age-

- Gender-

- Occupation-

- Subject-

- Years of experience-

Part 2

General Knowledge Regarding Dental Injuries

- Have you ever seen a tooth injury in a child?

- Yes

- No

- If yes, then which of the following injuries have you seen most commonly?

- Chipping of tooth segment.

- Discoloration/ Darkening of tooth.

- Knocking out of tooth.

- Loosening of tooth.

- Which sport is most commonly associated with dental injuries?

- Cricket

- Basketball

- Volleyball

- Kabaddi

- Handball

- Any other

- If a child falls and suffers from dental trauma, where should the child be taken in this case?

- To a general hospital.

- To a dental clinic.

- Child can be managed at school.

- Have you received training to manage dental trauma?

- Yes

- No

Part 3

Case Scenarios

Scenario 1

- If a child gets hit by a ball on his face and a small piece of his front tooth gets chipped off, what should be done in this case?

- The broken piece should be carried to the dentist.

- The broken piece should be carried to the dentist in a wet handkerchief.

- Don't know.

\section{Scenario 2}

- If a child falls down and his front tooth becomes loose, what should be done in this case?

- Try to fix the tooth.

- Try to pull the tooth out.

- Take emergency dental consultation.

\section{Scenario 3}

- If a 10-year-old child falls down while playing and his upper front tooth gets completely knocked out.

Would you identify the tooth as:

- Milk tooth

- Permanent tooth.

- In the above case how would you control the bleeding that results from the injury?

- By applying pressure on the affected area with a clean cloth or gauze.

- By applying pressure on the affected area with a cold tea bag.

- By putting ice cubes on the affected area.

- Any of the above.

- What can be done with the tooth that has been knocked out?

- The tooth can be picked up and be put back into the socket (Reimplantation).

- The child should be taken to the dentist along with the knocked out tooth.

- Nothing can be done once the tooth has been knocked out.

- How should the knocked out tooth be lifted up from ground?

- By the root

- By the crown

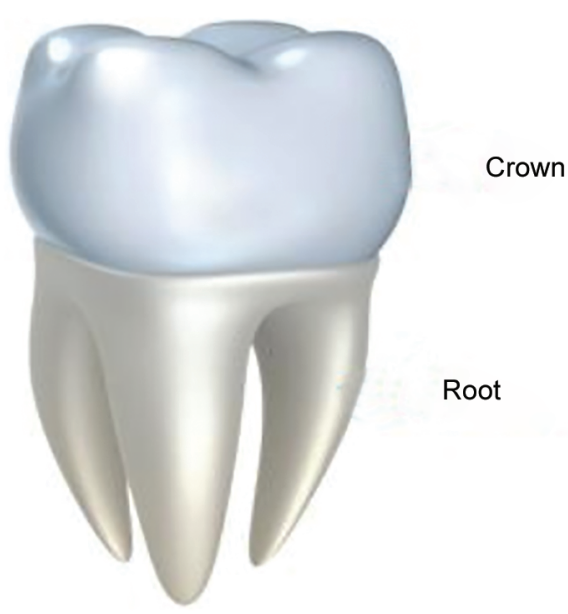

- If the tooth is to be put back into the socket, would you:

- Clean the tooth with soap.

- Rinse the tooth with water.

- Rub it vigorously with a toothbrush.

- If you decide to take the tooth to a dentist, which of the following is the most appropriate way to carry it?

- In a glass of water.

- In a glass of saline.

- In a clean cloth.

- In a glass of cold milk.

- If the reimplanted tooth has been picked up from a dirty ground, do you think it is necessary for the child to get a tetanus vaccine?

- Yes

- No

- How much time should you take to reach the dentist with a tooth that has fallen out? 
- Next day.

- Within 24 hours

- Within 30 mins of injury.

- If a 6-year-old child falls down and his upper front tooth gets knocked out, which tooth is this?

- Milk tooth

- Permanent

- Should a milk tooth be considered for reimplantation (putting back in the socket)?

- Yes

- No

Part 4

Self-assessment

- Do you feel you are efficient at handling dental trauma?

- Yes

- No

- Do you feel there's a need for seminars to be conducted in the school on emergency management of traumatic dental injuries?

- Yes

- No

\section{ResULts}

A total of 187 teachers responded to the questionnaire, with a response rate of $91.6 \%$. Majority of the teachers were females (76.47\%), and from the nonscience background (61.5\%).

About $75 \%$ of teachers agreed that they have witnessed a traumatic dental injury. Nearly $53 \%$ of teachers said they have mostly witnessed chipping of incisors, followed by tooth avulsion (10.7\%), tooth discoloration (9.06\%), and subluxation (4.23\%).

The most common sport associated with TDI was cricket (53.68\%) followed by Kabaddi (36.4\%), 89\% agreed that in case of a dental injury the child must be taken to a dental clinic, and less than $10 \%$ believed that the child can be managed at school.
Whereas, $88.23 \%$ teachers said that they haven't received any training for emergency management of dental trauma.

In the first case scenario, 55.08\% teachers believed that, in case of chipping of the incisors, it is advisable to carry the fractured segment in a wet handkerchief to the dentist, $30.51 \%$ did not find it necessary to carry it in a wet handkerchief while $14.41 \%$ were unsure of what is to be done in this case.

In the second case of luxation injury, $88.77 \%$ believed that the child should be taken for emergency dental consultation, $4.86 \%$ considered pulling out the tooth will be appropriate, and more than $6 \%$ chose to fix the tooth by themselves in this scenario.

In the third case, $67.38 \%$ correctly identified a knocked out tooth in a 10 -year-old as a permanent tooth. $28.6 \%$ believed that a clean cloth was the right choice, $22.4 \%$ believed that pressure by a cold tea bag was the best way to stop bleeding, $29.9 \%$ agreed to put ice on the bleeding site, but only $20.1 \%$ were aware that any of these could be effective to control bleeding resulting from the injury.

- Total of $61.5 \%$ teachers believed that a knocked out tooth can be replaced back into the socket, while $35 \%$ felt that nothing can be done once a tooth gets knocked out.

- About $49.73 \%$ said they would lift an avulsed tooth by the root while $46.52 \%$ found it appropriate to hold by the crown.

- Nearly $77.54 \%$ agreed that an avulsed tooth should be rinsed with water, $19.25 \%$ believed it should be rubbed with a tooth brush while $3.21 \%$ would wash it with soap. For this question surprisingly, the correct responses were significantly higher for the nonscience group.

- Around $53.7 \%$ opted to carry the tooth in water, $19.42 \%$ would carry the tooth in a cloth, while $12.5 \%$ agreed to carry it in saline. Only $14.44 \%$ agreed to carry the tooth in cold milk.

- A total of $77 \%$ of the teachers found it necessary to make sure that after reimplantation of an avulsed tooth child receives tetanus vaccine.

- About $65.24 \%$ of teachers chose to reach the dentist in 30 minutes of avulsion injury. $33.15 \%$ chose to reach the dental clinic by next day and the remaining opted to reach within 24 hours.

Table 1: Distribution of correct responses according to age of teachers

\begin{tabular}{lccc}
\hline No. of correct answers & Age $(<40 \mathrm{yrs})$ & Age $(>40 \mathrm{yrs})$ & Total \\
\hline$<5$ & 5 & 1 & 6 \\
& $(2.67)$ & $(0.53)$ & $(3.21)$ \\
$6-8$ & 23 & 36 & 59 \\
& $(12.30)$ & $(19.25)$ & $(31.55)$ \\
$9-11$ & 61 & 61 & 122 \\
& $(32.62)$ & $(32.62)$ & $(65.24)$ \\
Total & 89 & 98 & 187 \\
& $(47.59)$ & $(52.41)$ & $(100.00)$ \\
\hline
\end{tabular}

Table 2: Distribution of correct responses according to the subject of teachers

\begin{tabular}{lccc}
\hline No. of correct responses & Non-Science & Science & Total \\
\hline$<5$ & 5 & 1 & 6 \\
& $(2.67)$ & $(0.53)$ & $(3.21)$ \\
$6-8$ & 43 & 16 & 59 \\
& $(23.00)$ & $(8.56)$ & $(31.55)$ \\
$9-11$ & 67 & 55 & 122 \\
& $(35.83)$ & $(29.41)$ & $(65.24)$ \\
Total & 115 & 72 & 187 \\
& $(61.50)$ & $(38.50)$ & $(100.00)$ \\
\hline
\end{tabular}


- A great majority of teachers identified front tooth of a 6-year-old child as a milk tooth, but only $18.6 \%$ believed that it should not be replanted like a permanent tooth.

- Nearly $87.16 \%$ did not consider themselves efficient enough to handle dental trauma and $84.5 \%$ felt the need of a seminar on the same (Tables 1 to 3 ), (Figs 1 to 3 ).

\section{Discussion}

The present study was conducted amongst randomly selected schools in different parts of Jaipur among 220 teachers to assess their knowledge and awareness about emergency management of traumatic dental injuries in children.

The specific ages used in the case scenarios were taken keeping in mind the age at which the children are the most active and possess the highest risk of sports associated injuries.

In the present study only, $67.38 \%$ teachers were able to correctly identify the affected tooth. This is not in accordance with the studies conducted by Mohandas and Chandan ${ }^{6}$ at Bengaluru and Nirwan et al. ${ }^{2}$ at Jaipur, India ( $24.4 \%$ and $33.2 \%$, respectively).

Nearly $61.5 \%$ teachers believed that a knocked out tooth can be replaced back into the socket. This is in accordance with findings of studies conducted by Ahluwalia et al. ${ }^{7}$ at Patiala, Chandukutty et al. ${ }^{8}$ at Kerala, and Taranath et al. ${ }^{9}$ at Madurai, India, where a large number of school teachers (36.8\%, $83.8 \%$, and $99 \%$, respectively) were aware of possibility of reimplantation of tooth.

The ideal storage medium for an avulsed tooth should be capable of preserving PDL vitality, adherence, and clonogenic potential and should be easily accessible.
For the transport of avulsed tooth, most of the school teachers (53.7\%) opted to carry the tooth in water while only $14.4 \%$ chose to carry it in milk. This is in line with Hashim ${ }^{10}$ where only $4.3 \%$ school teachers, were aware of correct storage medium. Contrary to this, studies conducted by Ahluwalia et al., ${ }^{7}$ Chandukutty et al., ${ }^{8}$ Taranath et al. ${ }^{9}$ and Mohandas and Chandan ${ }^{6}$ found that a significant number of school teachers, that is, $47.4 \%, 40 \%, 35.7 \%$, and $49.6 \%$, respectively, were aware of appropriate storage medium.

It was encouraging to see that school teachers of Jaipur were aware of the critical role of time lapse after avulsion in managing the injury. About $65.24 \%$ of teachers chose to reach the dentist in 30 minutes of avulsion injury. Similar results were obtained from studies conducted by Chandukutty et al. ${ }^{8}$ and Taranath et al. ${ }^{9}$

When asked about the solution, they will use to clean the avulsed tooth with, $77.54 \%$ teachers opted to rinse the tooth with water. This was not in accordance by Mohandas and Chandan ${ }^{6}$ where only a few school teachers were aware of the correct solution to clean dirty avulsed tooth with.

About $87.16 \%$ did not consider themselves efficient enough to handle dental trauma and $84.5 \%$ felt the need of a seminar on the same. Programs to update teachers' knowledge about dental trauma management in addition to their training need to be included in teacher training programs. Further studies to assess and compare the knowledge and attitude regarding emergency management of dental trauma would give a broader perspective

The school teachers in India, besides imparting education, are becoming increasingly aware and are taking an active part in the proper healthcare of a child.

Table 3: Distribution of correct responses according to the years of experience of teachers

\begin{tabular}{lccc}
\hline & Experience in yrs & Experience in yrs & \\
No. of correct responses & $<15$ & $>15$ & Total \\
\hline$<5$ & 5 & 1 & 6 \\
& $(2.67)$ & $(0.53)$ & $(3.21)$ \\
$6-8$ & 29 & 30 & 59 \\
& $(15.51)$ & $(16.04)$ & $(31.55)$ \\
$9-11$ & 65 & 57 & 122 \\
& $(34.76)$ & $(30.48)$ & $(65.24)$ \\
Total & 99 & 88 & 187 \\
& $(52.94)$ & $(47.06)$ & $(100.00)$ \\
\hline
\end{tabular}

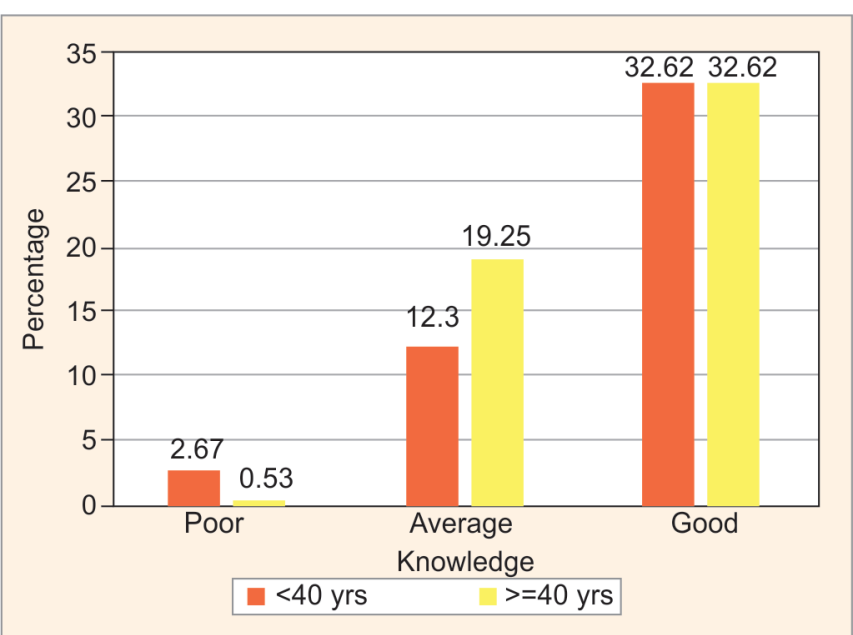

Fig. 1: Distribution of correct responses according to age of teachers

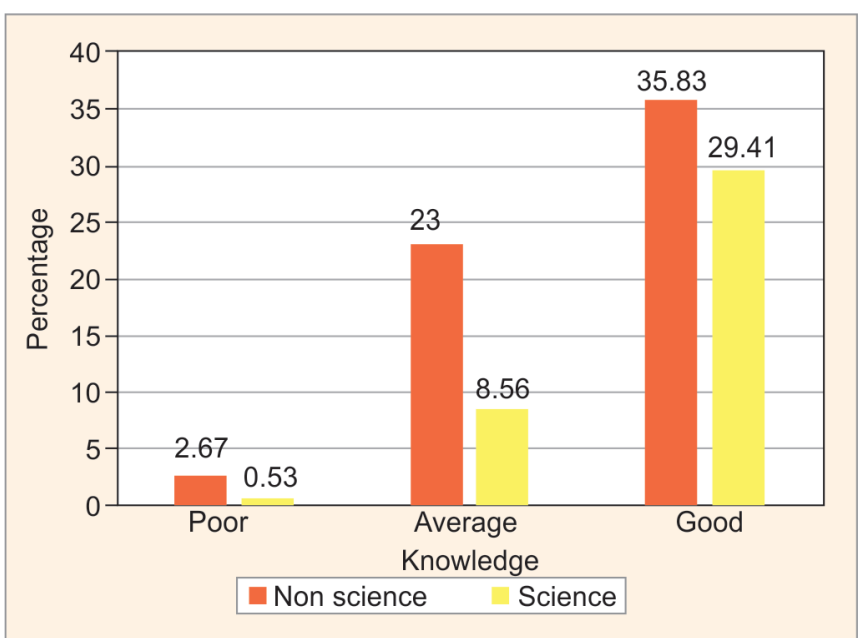

Fig. 2: Distribution of correct responses according to subject of teachers 


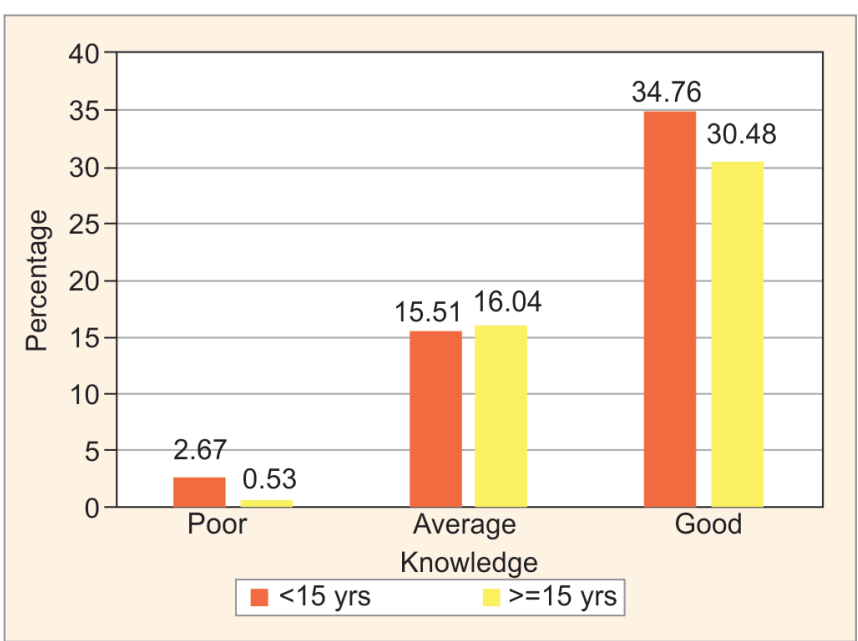

Fig. 3: Distribution of correct responses according to the years of experience of teachers

\section{Conclusion}

Within the limitations of the present study, results indicate that school teachers of Jaipur have a considerably good knowledge about emergency management procedures in case of traumatic dental injuries in children. And have a positive attitude toward learning and updating their knowledge regarding the same.

Teachers from the nonscience background seemed to have a better knowledge as compared to the ones from the science background. Similarly the ones below 40 years of age were better than the ones above 40 years.

\section{References}

1. Andreasen JO, Andreasen FM. Textbook and Color Atlas of Traumatic Injuries to the Teeth. 3rd ed. Copenhagen: Munksgaard, 1994.

2. Nirwan M, Syed AA, Chaturvedi S, et al. Awareness in primary school teachers regarding traumatic dental injuries in children and their emergency management: a survey in South Jaipur. Int J Clin Pediatr Dent 2016;9(1):62-66. DOI: 10.5005/jp-journals-10005-1335

3. Sharma A, Gupta R, Sharma S, et al. Dental trauma management and its awareness in school teachers: a survey in Burhanpur, Madhya Pradesh, India. Int J Appl Dent Sci 2018;4(4):371-375.

4. Vuletić $M$, Škaričić J, Batinjan $G$, et al. A retrospective study on traumatic dental and soft tissue injuries in preschool children in Zagreb, Croatia. Bosn J Basic Med Sci 2014;14(1):12-15. DOI: 10.17305/bjbms.2014.2284

5. Singh $M$, Ingle NA, Kaur $N$ et al. Evaluation of knowledge and attitude of school teachers about emergency management of traumatic dental injury. J Int Soc Prev Community Dent 2015;5(2):108-113. DOI: 10.4103/2231-0762.155735

6. Mohandas U, GD Chandan. Knowledge, attitude and practice in emergency management of dental injury among physical education teachers: a survey in Bangalore urban schools. J Indian Soc Pedod Prev Dent 2009;27(4):242-248. DOI: 10.4103/0970-4388.57660

7. Ahluwalia P, Pannu P, Kalra S, et al. Assessment of knowledge and attitudes of school teachers regarding emergency management of an avulsed permanent tooth. St Int Dent J 2015;1(1):16-21. DOI: $10.4103 / 2454-3160.161796$

8. Chandukutty D, Peedikayil FC, Premkumar CT, et al. Awareness of dental trauma management among school teachers of Kannur, Kerala, India. J Clin Diagn Res 2017;11(2):ZC08-ZC12. DOI: 10.7860/ JCDR/2017/19308.9252

9. Taranath M, Senaikarasi RM, Manchanda K. Assessment of knowledge and attitude before and after a health education program in East Madurai primary school teachers with regard to emergency management of avulsed teeth. J Indian Soc Pedod Prev Dent 2017;35(1):63-67. DOI: 10.4103/0970-4388.199218

10. Hashim R. Dental trauma management awareness among primary school teachers in the Emirate of Ajman, United Arab Emirates. Eur J Paediatr Dent 2011;12(2):99-102. 